\title{
ANALYSIS OF RESIDUE LEVELS IN KERNEL AND NUT WATER OF COCONUT PALMS INJECTED WITH MONOCROTOPHOS
}

\author{
C. S. RANASINGHE* ${ }^{*}$, W. P. K. K. FERNANDO', S. M. M. ZANEER ${ }^{2}$ and A. M. \\ MUBARAK $^{2}$ \\ ${ }^{1}$ Coconut Research Institute, Lunuwila. \\ ${ }^{2}$ Industrial Technology Institute, Colombo 07.
}

(Received: 24 October 2001 ; accepted: 09 December 2002)

\begin{abstract}
Monocrotophos (60\%), a systemic organophosphate insecticide, was injected into the trunk of coconut palms of 8-10 m height and 20 years of age at the rate of $20.0 \mathrm{ml}$ per palm. The residue levels of monocrotophos in coconut water and kernel at various stages of nut development and different durations after application, measured by GLC, showed that the residues were below the tolerance limit of $0.2 \mathrm{ppm}$ at 14 days after trunk injection.
\end{abstract}

Key words: Coconut, coconut kernel, coconut water, Cocos nucifera L., Monocrotophos, Monocrotophos residues, organophosphate insecticides, pesticide residues, systemic insecticides, trunk injection.

\section{INTRODUCTION}

The coconut palm (Cocos nucifera L.) is reported to be infested by more than 100 insect pests ${ }^{1}$ among which the black-headed coconut caterpillar (Opisina arenosella) and red weevil (Rhyncophorus ferrugineus) are the most serious. Many insecticides in the form of foliar spray, crown drenching, root feeding and trunk injection have been evaluated in India and Sri Lanka for the control of coconut caterpillar and red weevil, of which the trunk injection of monocrotophos was found to be the most effective. ${ }^{2-4}$ However, since monocrotophos is a highly toxic systemic insecticide, and coconut is consumed as tender nuts, kernel and kernel products (milk, DC, oil etc.), recommendations for chemical control of insect pests are incomplete if data on the residue status of monocrotophos in edible parts of coconut are not adequately provided. Some micro-bioassay and thin layer chromatographic methods used to determine the levels of monocrotophos in coconut water showed that the residues in mature nuts were below the tolerance limit of $0.2 \mathrm{ppm}$ set by the $\mathrm{WHO} / \mathrm{FAO},{ }^{5}$ three weeks after trunk injection of $20.0 \mathrm{ml}$ monocrotophos. ${ }^{6,7}$ However, a complete set of data on the residues in kernel and nut water of coconut of different maturity stages and harvesting periods after treatment is not available. Furthermore, all these previous studies have identified the necessity of conducting more accurate analyses of residues using advanced techniques, before any conclusions are made. Therefore, the aims of the present study were to determine the level of residues in edible parts of coconut at different maturity stages and

" Corresponding author 
different periods of harvest after trunk injection of monocrotophos, with a view to guiding both farmers and consumers to avoid a potential human hazard.

\section{METHODS AND MATERIALS}

Application of monocrotophos by trunk injection and sampling: Six bearing coconut palms (Cocos nucifera L. var. typica) of 8 to $10 \mathrm{~m}$ height and 20 years of age were selected at Bandirippuwa Estate, Lunuwila, and each was injected with $20.0 \mathrm{ml}$ of $600 \mathrm{~g} / \mathrm{L}$ Emulsifiable Concentrate (EC) monocrotophos (supplied by Mackwoods Ltd., Sri Lanka). The insecticide was applied into a hole of $15 \mathrm{~cm}$ depth, drilled at a horizontal angle of $45^{\circ}$ at a height of one meter from ground level. Two nuts from each bunch of a palm were picked to represent each stage of maturity. Sampling stages for kernel were 7 - 12 months of age, 7 being the youngest with developing kernel and 12 being the oldest. For nut water, the sampling stages were 4-12 months of age. The nuts were harvested 14, 30, 35 and 45 days after the monocrotophos application.

Analytical method: The analysis was done according to the method described by Their and Zeumer ${ }^{8}$ with some modifications, as given below (according to the moisture content of the kernel sample, the distilled water in the extracting solution was modified). Recovery studies showed that the method was satisfactory for both kernel and nut water at the limit of determination (kernel - 0.1 ppm; nut water - 0.01 ppm; recovery obtained for 1,2 and 4 ppm monocrotophos solutions was $98 \%$ ).

Extraction and purification of kernel for residue analysis: $50 \mathrm{~g}$ of scraped kernel were homogenized with $100.0 \mathrm{ml}$ of acetone and $10.0 \mathrm{ml}$ of distilled water for $3 \mathrm{~min}$. Celite $(10 \mathrm{~g})$ was added to the homogenate and mixed for $1 \mathrm{~min}$. The homogenate was filtered using a Buchner funnel and washed with $50.0 \mathrm{ml}$ of acetone. A volume equivalent to $20 \mathrm{~g}$ of kernel was transferred from the filtrate to a separating funnel. This was saturated with $\mathrm{NaCl}$, partitioned twice with $60 \mathrm{ml}$ and $40 \mathrm{ml}$ of dichloromethane respectively, and left to stand for $10 \mathrm{~min}$. The separated organic phase was passed through a column of anhydrous sodium sulphate $(30 \mathrm{~g})$. The eluent was concentrated to $2.0 \mathrm{ml}$ in a rotary evaporator and the traces of solvent left were removed with a gentle stream of air. The samples were then passed through a gel permeation column (Bio-Beads S-X3 $50 \mathrm{~g}, 1 \mathrm{~m}$ length, $25 \mathrm{~mm}$ id) and eluted with dichloromethane: cyclohexane (1:1). The eluting volume for monocrotophos was determined to be $110-155 \mathrm{ml}$ by using standards. The eluent was collected and concentrated to $1.0 \mathrm{ml}$ in a rotary evaporator.

Extraction and purification of nut water for residue analysis: $100 \mathrm{ml}$ of nut water were saturated with $\mathrm{NaCl}$ and partitioned twice with 60 and $40 \mathrm{ml}$ of dichloromethane. The separated organic phase was passed through a column of anhydrous sodium sulphate $(30 \mathrm{~g})$. The eluent was concentrated to $2.0 \mathrm{ml}$ in a rotary evaporator. 
Analysis of kernel and nut water samples for monocrotophos residues: The kernel and nut water samples were dissolved in a known volume of acetone and analysed using a gas liquid chromatograph (VARIAN, USA) equipped with Chromosorb WHP $80 / 100$ column (length $1 \mathrm{~m}$, id $2 \mathrm{~mm}$ ) and TSD.

\section{RESULTS}

Irrespective of the stage of maturity or date of harvest, the residue levels of monocrotophos in coconut kernel were always less than the detectable limit of $0.1 \mathrm{ppm}$ and tolerance limit of $0.2 \mathrm{ppm}$ set by the WHO / FAO (Table 1).

Table 1: Residues of monocrotophos in coconut kernel (ppm) at different maturity stages and different periods of harvest after trunk injection

\begin{tabular}{ccccc}
\hline $\begin{array}{c}\text { Bunch No. } \\
\text { (age-months })\end{array}$ & \multicolumn{4}{c}{ Days after monocrotophos injection } \\
\cline { 2 - 5 } & 14 & 30 & 35 & 45 \\
\hline 6 & $<0.1$ & $<0.1$ & $<0.1$ & $<0.1$ \\
7 & $<0.1$ & $<0.1$ & $<0.1$ & $<0.1$ \\
8 & $<0.1$ & $<0.1$ & $<0.1$ & $<0.1$ \\
9 & $<0.1$ & $<0.1$ & $<0.1$ & $<0.1$ \\
10 & $<0.1$ & $<0.1$ & $<0.1$ & $<0.1$ \\
11 & $<0.1$ & $<0.1$ & $<0.1$ & $<0.1$ \\
12 & $<0.1$ & $<0.1$ & $<0.1$ & $<0.1$ \\
\hline
\end{tabular}

$\mathrm{L}_{\mathrm{DM}}=$ Limit of determination for kernel $0.1 \mathrm{ppm}$

The monocrotophos residues in coconut water at all stages of maturity or date of harvest sampled remained lower than the tolerance limit of $0.2 \mathrm{ppm}$ set by the WHO / FAO. However, irrespective of the date of harvest, the highest residue level was observed in the nut water of maturity stage 4 . During the tender nut stage (maturity stage 7-8 months), trace amounts of monocrotophos residues were detected in the nut water for a period of 45 days after injection, but the levels were far below the tolerance limit of $0.2 \mathrm{ppm}$. In the nuts of maturity stage 10 and above, the residues in nut water were álways below the detectable limit of $0.01 \mathrm{ppm}$ (Table 2). 
Table 2: Residues of monocrotophos in coconut water (ppm) at different maturity stages and different periods of harvest after trunk injection (meann \pm std. deviations are given)

\begin{tabular}{ccccc}
\hline $\begin{array}{c}\text { Bunch No. } \\
\text { (age-months })\end{array}$ & \multicolumn{4}{c}{ Days after monocrotophos injection } \\
\cline { 2 - 5 } & 14 & 30 & 35 & 45 \\
\hline 4 & $0.17 \pm .018$ & $0.12 \pm .010$ & $0.11 \pm .016$ & $0.09 \pm .011$ \\
5 & $0.07 \pm .011$ & $0.11 \pm .013$ & $0.10 \pm .018$ & $0.09 \pm .014$ \\
6 & $0.06 \pm .017$ & $0.08 \pm .011$ & $0.09 \pm .012$ & $0.07 \pm .014$ \\
7 & $<0.01$ & $0.01 \pm .010$ & $0.06 \pm .012$ & $0.06 \pm .011$ \\
8 & $<0.01$ & $0.01 \pm .010$ & $0.03 \pm .018$ & $0.06 \pm .011$ \\
9 & $<0.01$ & $<0.01$ & $<0.01$ & $0.02 \pm .012$ \\
10 & $<0.01$ & $<0.01$ & $<0.01$ & $<0.01$ \\
11 & $<0.01$ & $<0.01$ & $<0.01$ & $<0.01$ \\
12 & $<0.01$ & $<0.01$ & $<0.01$ & $<0.01$ \\
\hline
\end{tabular}

$\mathrm{L}_{\mathrm{DM}}=$ Limit of determination for nut water $0.01 \mathrm{ppm}$

\section{DISCUSSION}

Mithyanatha et al., ${ }^{9}$ worked out the monocrotophos residue content in coconut water and copra of mature nuts based on the estimation of total phosphorus and found the residues below detectable levels in the third week after treatment. That study reported the monocrotophos residue to be below the prescribed tolerance limit of 0.2 ppm one week after treatment. Nadarajan et al., ${ }^{2}$ also reported the monocrotophos residue in coconut to be below the tolerance limit, three weeks after treatment. Using a bioassay, Patel et al., ${ }^{6}$ analysed the residue levels of nut water at various intervals after application of monocrotophos using the trunk injection technique and revealed that it was above the tolerance limit up to a period of three weeks and declined below detectable levels after four weeks of treatment. These results indicated that coconut water is safe for drinking with respect to monocrotophos only after the fourth week of treatment. Similar work by Kanagaratnam et al., ${ }^{7}$ at the Coconut Research Institute of Sri Lanka (CRISL) using tender and mature nuts, revealed that the levels of monocrotophos residues in the nut water were well within the tolerance limit of $0.2 \mathrm{ppm}$ approved by the FAO / WHO, irrespective of the date of harvest. Further, they showed that residues in the kernel were very low, 
and especially emphasized that the sensitivity of the method used for analysis (TLC) was inadequate for an accurate study of residue levels.

In our study, the application of monocrotophos at $20.0 \mathrm{ml}$ per palm by trunk injection was found to result in residue levels below the tolerance limit of $0.2 \mathrm{ppm}$ after 14 days of application. The present findings are therefore incompatible with those reported by Mithyanatha et al.,. ${ }^{9}$ Future studies are planned to determine the fate of monocrotophos in the coconut palm using radio-isotope techniques (with radiolabeled monocrotophos).

\section{Acknowledgement}

We are most grateful to the CRI and the ITI for providing the facilities to conduct this experiment. The co-operation and assistance extended by the staff of the Plant Physiology Division, Coconut Research Institute and the Chemical and Environmental Technology Division, ITI in conducting the experiment are also gratefully acknowledged.

\section{References}

1 Nirula K. K. (1955). Investigation on the pests of coconut palm Part I. Indian Coconut Forum. 8 (3): 188-230.

2 Nadarajan L., Chann Basavanna G. P. \& Nagesh Chandra B. K. (198

0 ). Control of coconut pests through stem injection of systemic insecticides. Mysore Journal of Food and Agricultural Science 14 (3): 355-364.

3 Kanagaratnam P. \& Pinto J. L. J. G. (1985). Effect of monocrotophos on the leaf-eating caterpillar, Opisina arenosella Walk, when injected into the trunk of the coconut palm. Cocos 3: 9-15.

4 Rajapakse C.N.K. \& Kanagaratnam P. (1988). Evaluation of three systemic insecticides and three methods of application for the control of red palm weevil, Rhynchophorus ferrugineus Oliv (Coleoptera, Curculionidae). Proceedings of the Annual Sessions of the Sri Lanka Association for the Advancement of Science, (December 1988) p. 68.

5 Anonymous (1972). Pesticide residues in food. F.A.O. Agricultural Studies No. 88, F.A.O. Rome.

6 Patel R. K., Shah A. H. \& Jhala R. C. (1985). Residue status of monocrotophos in coconut water injected by stem injection technique. GAU Research Journal 10 (2): $16-22$. 
7 Kanagaratnam F., Mubarak A. M., Gunewardane H. P. G. \& Croos W. P. K. K. (1987). Detection of pesticide residues in kernel and nut water from palms treated with systemic insecticides by bioassay using Drosophila sp. Annual Report of CRI, Sri Lanka, pp. 129-131.

8 Hans-Peter Their \& Han\$ Zeumer (1987). Manual of Pesticide Residue Analysis vol 1 (2): 382-400. Pesticide Commission.

9 Mithyanatha M. S., Chann Basavanna G. P. \& Nagesh Chandra B. K. G. P. (1980). Studies on residues of some systemic insecticides in coconut water and copra. Pesticides residues in the environment in India, U. A. S. Technical Series 32: 295-298. 